Abstract-Understanding postrelease effects of incidental capture on fish species of conservation concern is critically needed. We collaborated with commercial fishermen to estimate postrelease survival of green sturgeon (Acipenser medirostris) captured and released from bottom trawls used to target California halibut (Paralichthys californicus). We developed a method for interpreting acceleration, depth, and temperature data transmitted from pop-up satellite archival tags to classify the fate of individuals following capture and release in fishing operations. We first deployed SeaTag-MOD satellite tags on known living and dead sturgeon to develop a support vector machine that uses accelerometer readings to classify tagged fish as alive or dead. In 2015 and 2016, fishermen and West Coast Groundfish Observer Program observers tagged 76 green sturgeon (69-135 cm fork length) encountered as bycatch, yielding 51 useable data sets. Eleven sturgeon were classified as having died after release, 9 of which died within our designated 21-d (504 h) study period. Some green sturgeon entered the San Francisco Bay Delta after being tagged, indicating movement between ocean and estuary environments. Research is needed to understand how to minimize effects of handling time and trawl bycatch mortality.

\section{Postrelease survival of green sturgeon (Acipenser medirostris) encountered as bycatch in the trawl fishery that targets California halibut (Paralichthys californicus), estimated by using pop-up satellite archival tags}

\author{
Phaedra Doukakis (contact author) ${ }^{1}$ \\ Ethan A. Mora (deceased) ${ }^{2,3}$ \\ Susan Wang ${ }^{4}$ \\ Paul Reilly \\ Russ Bellmer (retired) ${ }^{5}$ \\ Kristine Lesyna ${ }^{6}$ \\ Travis Tanaka ${ }^{5}$ \\ Natnael Hamda ${ }^{2,3}$
}

\author{
Mary L. Moser ${ }^{7}$ \\ Daniel L. Erickson' \\ Jason Vestre ${ }^{8}$ \\ Jon McVeigh ${ }^{8}$ \\ Kevin Stockmann 8 \\ Kristen Duncan ${ }^{8}$ \\ Steven T. Lindley ${ }^{2}$
}

Email address for contact author: phaedra.doukakis@noaa.gov

${ }^{1}$ Ocean Associates Inc. National Marine Fisheries Service, NOAA 4007 North Abingdon Street Arlington, Virginia 22207

${ }^{2}$ Southwest Fisheries Science Center National Marine Fisheries Service, NOAA 110 McAllister Way Santa Cruz, California 95060

${ }^{3}$ Cooperative Institute for Marine Ecosystems and Climate

University of California Santa Cruz

1156 High Street

Santa Cruz, California 95060

${ }^{4}$ West Coast Region

National Marine Fisheries Service, NOAA

501 West Ocean Boulevard, Suite 4200

Long Beach, California 90802
${ }^{5}$ Fisheries Branch California Department of Fish and Wildlife 830 S Street

Sacramento, California 95814

${ }^{6}$ Belmont Field Office and Laboratory Marine Region California Department of Fish and Wildlife 350 Harbor Boulevard Belmont, California 94002

${ }^{7}$ Northwest Fisheries Science Center National Marine Fisheries Service, NOAA 2725 Montlake Boulevard East Seattle, Washington 98112

${ }^{8}$ West Coast Groundfish Observer Program Northwest Fisheries Science Center National Marine Fisheries Service, NOAA 2725 Montlake Boulevard East Seattle, Washington 98112
Manuscript submitted 29 April 2019. Manuscript accepted 18 February 2020. Fish. Bull. 118:63-73 (2020).

Online publication date: 13 March 2020. doi: 10.7755/FB.118.1.6

The views and opinions expressed or implied in this article are those of the author (or authors) and do not necessarily reflect the position of the National Marine Fisheries Service, NOAA.
Quantifying the impacts of incidental capture and release on marine species is a difficult but critical fisheries management requirement (Davis, 2002; Suuronen, 2005; Davies et al., 2009; Brooke et al., 2012). Fish encountered as bycatch may experience effects such as delayed mortality or reductions in fitness (Davis, 2002; Suuronen, 2005; Suuronen and Erickson, 2010; Wilson et al., 2014). Delayed mortality can be an important factor in the recovery of fish listed under the U.S. Endangered Species Act (Collins et al., 2000; ASSRT, 2007).

Postrelease survival in fish species has traditionally been examined by holding fish in net pens after capture (e.g., Davis, 2002; Parker et al., 2003; Weltersbach and Strehlow, 2013), 
using experimental gear (e.g., Erickson and Pikitch ${ }^{1}$ ), or studying fish activity through telemetry (Hoolihan et al., 2011; Beardsall et al., 2013; Campana et al., 2016). Common factors contributing to mortality in these and other studies include time out of water on deck, water and air temperature, tow velocity and duration, and fish size and handling practices (Olla et al., 1997; Davis et al., 2001; Davis and Parker, 2004; Suuronen and Erickson, 2010; Gale et al., 2013; Mandelman et al., 2013). Predation after release can also be a factor (Raby et al., 2014). Cook et al. (2019) reviewed potential sources of stress that lead to postrelease mortality and predation in fish species. They observed that simulating actual fishery practices is critical for correctly assessing bycatch effects.

Involving the fishing community in fisheries research has many benefits (Johnson and van Densen, 2007; Yochum et al., 2011). Cooperative research can facilitate enhanced knowledge of the fisheries resource while engendering trust and communication among policymakers, scientists, and fishermen. Moreover, involving the fishing community can increase data collection capacity and validity. Fishermen may also become more invested in the results and willing to address conservation challenges.

Sturgeon and paddlefish species (Acipenseriformes) are among the most threatened of all fish families, according to the IUCN Red List of Threatened Species (IUCN, 2018). Historic overfishing, illegal fishing and trade, and habitat modification and destruction have contributed to their decline (Pikitch et al., 2005). Although directed catch has been eliminated for most sturgeon species, mortality due to incidental capture still threatens the recovery of depleted populations (Stein et al., 2004; Beardsall et al., 2013; Dunton et al., 2015; Breece et al., 2016).

Green sturgeon (Acipenser medirostris) inhabit coastal bays, estuaries, rivers, and nearshore environments along the western seaboard of North America and are taken as bycatch in a number of fisheries (NMFS, 2015; $\mathrm{NMFS}^{2}$ ). Bycatch of green sturgeon is a factor in recovering the Southern distinct population segment (DPS), which is listed as threatened under the Endangered Species Act (Federal Register, 2006; NMFS $^{2}$ ). The Southern DPS recovery plan recognizes reducing fisheries bycatch and estimating postrelease effects as priority tasks $\left(\mathrm{NMFS}^{2}\right)$. The Northern DPS of green sturgeon, a National Marine Fisheries Service (NMFS) species of concern (Federal Register, 2006), coexists with the Southern

\footnotetext{
${ }^{1}$ Erickson, D., and E. Pikitch. 1999. Survival of trawl-caught and discarded sablefish, 21 p. Northwest Fish. Sci. Cent., Natl. Mar. Fish. Serv., NOAA, Newport, OR. [Available from Northwest Fish. Sci. Cent., 2725 Montlake Blvd. E., Seattle, WA 98112.]

2 NMFS (National Marine Fisheries Service). 2018. Recovery plan for the Southern distinct population segment of North American green sturgeon (Acipenser medirostris), 88 p. Calif. Cent. Valley Off., West Coast Reg., Natl. Mar. Fish. Serv., NOAA, Sacramento, CA. [Available from website.]
}

DPS in estuarine and marine habitats $\left(\mathrm{NMFS}^{2}\right)$, and fish from the 2 DPS are morphologically indistinguishable $\left(\mathrm{NMFS}^{2}\right)$. Directed fishing has been virtually eliminated for green sturgeon in West Coast rivers and nearshore environments because coast-wide regulations prohibit retention $\left(\mathrm{NMFS}^{2}\right)$.

The bottom-trawl fishery that targets California halibut (Paralichthys californicus) and operates out of San Francisco and Half Moon Bay, California, encounters green sturgeon at a rate higher than that of other fisheries for which we have data (Richerson et al. ${ }^{3}$ ). The NMFS West Coast Groundfish Observer Program (WCGOP) has recorded bycatch of green sturgeon in the fishery since 2002. Between 2007 and 2017, estimated annual encounters of green sturgeon in the fishery ranged from 29 individuals in 2011 to 665 individuals in 2015. Analysis of genetic samples taken from specimens of the green sturgeon caught in the fishery over that time period $(n=104)$ indicates that over $95 \%$ of the animals encountered are from the threatened Southern DPS (Anderson et al., 2017). The majority of green sturgeon encountered in the fishery are immature individuals that are less than $140 \mathrm{~cm}$ fork length [FL] and greater than $59 \mathrm{~cm}$ FL (Richerson et al. ${ }^{3}$ ). Southern DPS green sturgeon reproduce in the Sacramento River system and rear in the San Francisco Bay Delta $\left(\mathrm{NMFS}^{2}\right)$. The fishery operates in waters of the Pacific Ocean more than $5.6 \mathrm{~km}$ (3 nautical miles) offshore from this delta (Fig. 1). Immediate mortality of green sturgeon in the fishery (i.e., finding dead green sturgeon in the bottomtrawl net) is only very rarely observed in WCGOP onboard sampling.

We collaborated with fishermen that target California halibut and with WCGOP observers to measure postrelease survival of green sturgeon encountered in the California halibut bottom-trawl fishery. We developed a method for interpreting data transmitted from pop-up satellite archival tags (PSATs) to classify the fate of green sturgeon after release and were able to estimate postrelease survival in normal California halibut bottom-trawl operations. We tested the hypothesis that there is no postrelease mortality of green sturgeon captured as bycatch in this fishery.

\section{Material and methods}

We had 3 objectives: 1) characterize the patterns of tag sensor data (accelerometer data) of known living and dead green sturgeon, 2) train an algorithm to classify accelerometer data into alive and dead classes, and 3) use the

\footnotetext{
${ }^{3}$ Richerson, K., J. E. Jannot, Y.-W. Lee, J. McVeigh, K. Somers, V. Tuttle, and S. Wang. 2019. Observed and estimated bycatch of green sturgeon in 2002-2017 U.S. West Coast groundfish fisheries. Northwest Fish. Sci. Cent. Observer Program, Natl. Mar. Fish. Serv., NOAA, Seattle, WA. [Available from website.]
} 


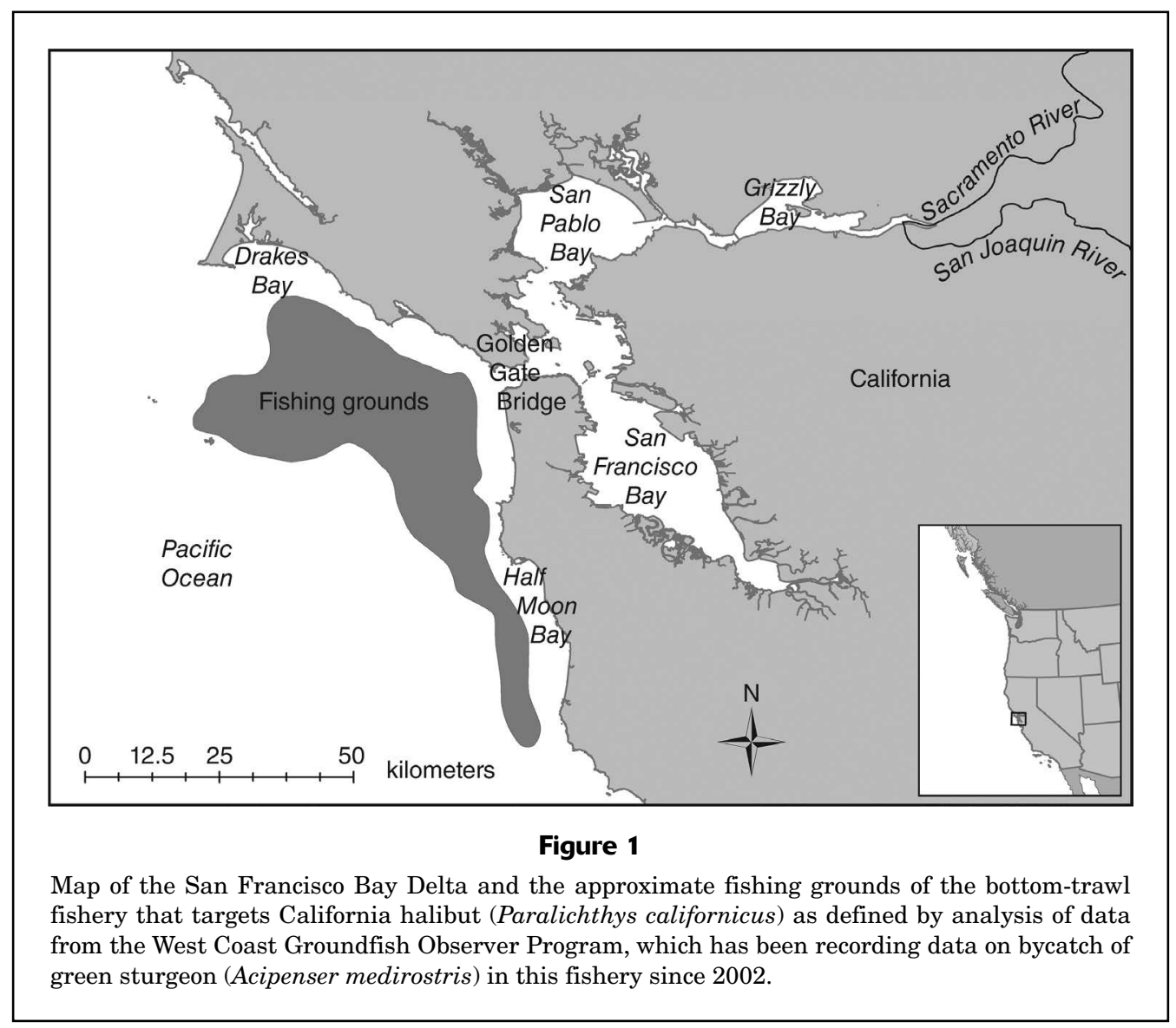

algorithm along with other information to classify the fate of green sturgeon captured and released during normal fishing operations of the bottom-trawl fishery that targets California halibut (Fig. 2).

During 2015 and 2016, green sturgeon were captured and tagged in the bottom-trawl fishery that operates out of San Francisco, California, and Half Moon Bay, California, and targets California halibut (Fig. 1). We used PSATs (SeaTag-MOD ${ }^{4}$ tags, Desert Star Systems, Marina, CA) to log acceleration on 3 axes, along with tag depth and water temperature. In all cases, the tags were attached to the base of the dorsal fin of the sturgeon by using clear 2-mm monofilament fishing line crimped into a loop of approximately $150 \mathrm{~mm}$ (Erickson and Hightower, 2007). This loose attachment allowed the tags to float vertically above the dorsal fin when the fish was stationary, trail freely alongside or above the fish when the fish was swimming, and undulate with the tailbeat. The tags were programmed to log readings from the sensors every $4 \mathrm{~min}$. The length of tag deployment (number of days attached to the fish) varied for each objective.

\footnotetext{
${ }^{4}$ Mention of trade names or commercial companies is for identification purposes only and does not imply endorsement by the National Marine Fisheries Service, NOAA.
}

\section{Characterizing sensor readings for green sturgeon with known fates}

To characterize the data patterns of living and dead green sturgeon, we attached PSATs to known living and dead sturgeon in 2 separate trials (Suppl. Table 1). In the first trial, we attached PSATs to 3 living, captive green sturgeon (approximately 90, 100, and $110 \mathrm{~cm} \mathrm{FL)} \mathrm{held}$ for $7.5 \mathrm{~h}$ in a $1.5-\mathrm{m}$ deep circular tank with a $4-\mathrm{m}$ diameter. The fish swam naturally during the trial, and the position of tags ranged from vertical when the fish were stationary to nearly vertical (partially horizontal) when the fish were mobile. In the second trial, we attached a PSAT to a dead white sturgeon (A. transmontanus) (104 cm FL) in the Pacific Ocean off northern California for $96 \mathrm{~h}$.

We used accelerometer readings, from PSAT deployments for which the fates of fish were known, to train the support vector machine (SVM) and to classify individuals on the basis of data patterns into 1 of 2 states: alive or dead. The SVM is a machine-learning algorithm designed for binary classification (Burges, 1998; Bishop, 2006; Raschka, 2015; Sugiyama, 2016; Watt et al., 2016). After training and testing the SVM, we developed a classification workflow by using Scikit-learn (vers. 0.18.1; Pedregosa et al., 2011) for implementing the algorithm. 


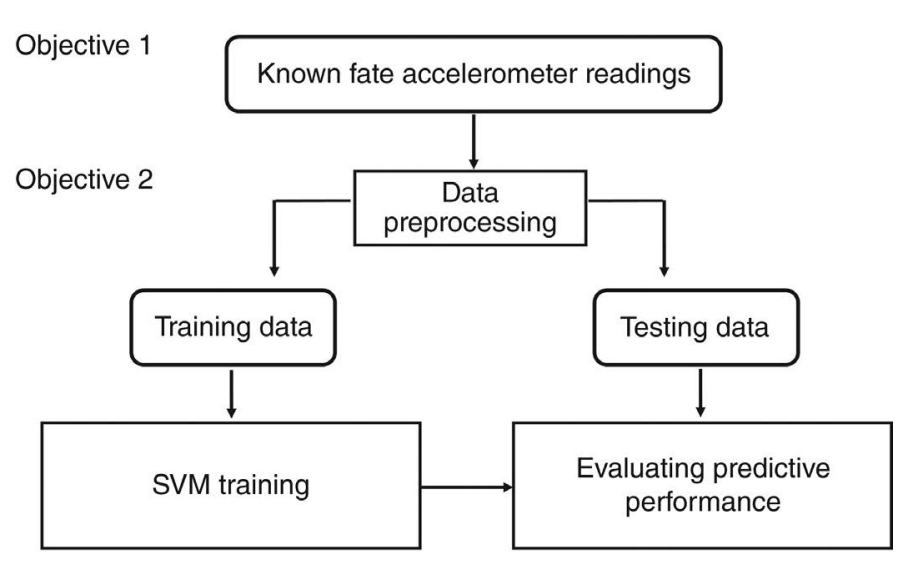

Objective 3

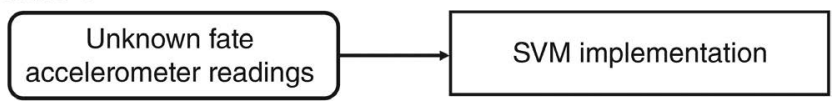

Figure 2

Schematic description of the model development and implementation process used to estimate postrelease survival of green sturgeon (Acipenser medirostris) in the bottom-trawl fishery that targets California halibut (Paralichthys californicus) in nearshore waters of the Pacific Ocean just west of the San Francisco Bay Delta. The first objective was to characterize the patterns of tag sensor data (accelerometer readings) of green sturgeon with known fates. The second objective was to train an algorithm, a support vector machine (SVM), to classify accelerometer data into alive and dead classes. The third objective was to use the algorithm along with other information to classify the fate of green sturgeon captured and released from May 2015 through September 2016 during normal fishing operations of the California halibut bottom-trawl fishery.

The SVM constructs 2 hyperplanes (decision boundaries) that separate binary classes while preserving the greatest margin between them. The margin is defined as the distance between the hyperplanes and the data points closest to a hyperplane (support vectors) (Raschka, 2015). If we assume that the 2 classes are linearly separable, the objective is to find hyperplanes with the smallest generalization error between observations from accelerometer data and predictions from the model (the SVM).

The positive (living) and negative (dead) individuals and hyperplanes that are parallel to the decision boundary can be mathematically expressed as follows:

$$
\begin{aligned}
& W_{0}+W^{\mathrm{T}} X_{\text {pos }}=1 \text { and } \\
& W_{0}+W^{\mathrm{T}} X_{\text {neg }}=-1,
\end{aligned}
$$

where $W_{0}=$ a bias factor;

$W=$ a vector that weights values for each set of accelerometer readings;

$\mathrm{T}=$ the transpose of the vectors $W$;

$X_{\mathrm{pos}}=$ accelerometer readings for the positive (living) individuals; and

$X_{\text {neg }}=$ accelerometer readings for the negative (dead) individuals.
The goal is to train the SVM for optimal classification of fish as positive or negative while iteratively estimating $W$. Therefore, the separation problem is to determine the hyperplane such that

$$
\begin{aligned}
& W_{0}+W^{\mathrm{T}} X_{\text {pos }} \geq 1 \text { and } \\
& W_{0}+W^{\mathrm{T}} X_{\text {neg }} \leq-1 .
\end{aligned}
$$

If we subtract Equation 1 from Equation 2, we get the following equation:

$$
W^{\mathrm{T}}\left(X_{\text {pos }}-X_{\text {neg }}\right)=2 .
$$

The length of the vector $(w)$ can be defined as follows:

$$
\|w\|=\sqrt{\sum_{\mathrm{j}=1}^{\mathrm{m}} w_{\mathrm{j}}^{2}} .
$$

Normalizing Equation 5 by using the length of the vector $w$, we arrive at Equation 7:

$$
\frac{W^{\mathrm{T}}\left(X_{\mathrm{pos}}-X_{\text {neg }}\right)}{\|w\|}=\frac{2}{\|w\|} .
$$

The SVM finds the hyperplane that has the largest margin, by maximizing Equation 7 and constraining the samples of data so that they are classified correctly as follows:

$$
\begin{aligned}
& W_{0}+W^{\mathrm{T}} x^{(\mathrm{i})} \geq 1 \quad \text { if } y^{(\mathrm{i})}=1 \text { and } \\
& W_{0}+W^{\mathrm{T}} x^{(\mathrm{i})}<-1 \text { if } y^{(\mathrm{i})}=-1,
\end{aligned}
$$

where $y^{(\mathrm{i})}=$ the data classes (i.e., the dependent variables); and

$$
x^{(\mathrm{i})}=\text { accelerometer readings. }
$$

The constraint equation requires that negative data points fall on one side of the negative hyperplane and that positive data points fall behind the positive hyperplane. Here, the hyperplanes correspond to alive and dead classifications as follows:

$$
y^{(\mathrm{i})}\left(W_{0}+W^{\mathrm{T}} x^{(\mathrm{i})}\right) \geq 1 .
$$

This mathematical approach assumes the data separated by the hyperplane are linearly separable. However, this assumption fails for our data set. To address this issue, we used a modified kernel method in which kernel functions $K\left(X^{(\mathrm{i})}, X^{(\mathrm{j})}\right)$ transform the training data (Burges, 1998; Bishop, 2006; Raschka, 2015; Watt et al., 2016). This method creates nonlinear combinations of the original features to project them onto a higher dimensional space where they become linearly separable (Bishop, 2006; Raschka, 2015). We applied the radial basis function kernel, also known as the Gaussian kernel (Equation 11):

$$
K\left(x^{(\mathrm{i})}, x^{(\mathrm{j})}\right)=\mathrm{e}^{\left(\frac{\left\|x^{(\mathrm{i})}-x^{(\mathrm{j})}\right\|}{2 \sigma^{2}}\right)} .
$$


Here, $\gamma=\frac{1}{2 \sigma^{2}}$ is a free parameter (hyperparameter) that is to be optimized.

\section{Training and testing the algorithm}

The accelerometer readings obtained in the work for our first objective were randomly divided into training and testing data samples at a ratio of 4:1 (training:testing). Prior to the training and testing process, the samples of tag sensor data $\left(X_{\mathrm{i}}\right)$ were transformed to $X_{\text {std,i }}$ by using their respective means $\left(\mu_{\mathrm{i}}\right)$ and standard deviations $\left(\sigma_{\mathrm{i}}{ }^{2}\right)$ with the following equation:

$$
X_{\mathrm{std}, \mathrm{i}}=\frac{\left(X_{\mathrm{i}}-\mu_{\mathrm{i}}\right)}{\sigma_{\mathrm{i}}} .
$$

The goal of normalization is to change the accelerometer readings to a common scale without distorting differences in the ranges of values. The standardization step avoids biasing the machine-learning algorithm toward numerically large values. After normalization, the model was trained by using the SVMs in Scikit-learn. We used the stochastic gradient-descent optimization technique to estimate the model parameters. To avoid over-fitting, we applied a 10-fold cross-validation technique (Sugiyama, 2016) in which the training data set was divided into 10 groups and the model was trained iteratively by using 9 groups and validated with the remaining group. After training, the model was implemented to test classification accuracy.

During the training and testing of the model, we encountered data imbalance between the alive and dead classes. Among the 1676 data points we obtained, only 284 data points (less than 17\%) were labeled as alive because the tag deployment on living green sturgeon was $7.5 \mathrm{~h}$. In contrast, the dead white sturgeon was monitored for $96 \mathrm{~h}$. Because this data imbalance can lead to a biased classification performance (Murphy, 2012), we resampled the alive class and randomly replicated it to increase the number of data points for this class in the sample. To avoid over-fitting, we evaluated the performance of the SVM classifier by using precision as an additional classification metric. By combining the 2 classification performance metrics (i.e., accuracy and precision), we were able to balance the bias-variance tradeoff of the SVM classifier.

Once trained, we used the classification algorithm to assist with the interpretation of accelerometer data from deployments on green sturgeon captured as bycatch in the commercial California halibut bottomtrawl fishery.

\section{Classifying fates of captured green sturgeon}

To apply our model and measure postrelease survival, green sturgeon were captured as bycatch on 6 bottomtrawl vessels during normal fishing operations that targeted California halibut and tagged with PSATs between 13 May 2015 and 7 September 2016 (Fig. 1). Sturgeon tagged with PSATs were measured (in FL) and released as soon as possible. To encourage return of the tags for enhanced data recovery and redeployment, PSATs had a reward label.

From fish handled by an observer, we collected a tissue sample (1- $\mathrm{cm}^{2}$ clip from the pectoral fin) for genetic analysis to determine whether the fish belonged to the Southern or Northern DPS. No live wells were available on the cooperating vessels; green sturgeon were removed from the haul and processed as soon as possible. We rated the condition of the fish as good (no apparent damage or stress), fair (flushed appearance, minor abrasions), or poor (serious abrasions, bleeding, or obvious injury) (NWFSC ${ }^{5}$ ) and recorded the additional time on deck needed for WCGOP processing and tagging (i.e., obtaining weight, length, fin clip, and photograph, and tagging with passive integrated transponder tags, in some cases, and PSATs). We recorded the date, time, and GPS location at which each fish was released as well as the associated trip and haul number. For each haul, we recorded the starting and ending dates, times, locations, and depths.

Initially, multiple fish in a single haul were tagged, and tagged fish were as small as $69 \mathrm{~cm}$ FL. Concern over introducing confounding factors (e.g., extended time on deck when tagging multiple fish and potential tag effects on smaller fish) led to changes in our protocol to tag only fish $\geq 80 \mathrm{~cm}$ FL in each haul. We tagged the first captured fish of sufficient size. Prior to these changes, the maximum number of fish tagged in a single haul was 3 , and this number was taken only once; 2 fish were tagged in each of 5 other hauls. All other hauls had either 1 fish in the haul or had only 1 fish tagged out of multiple individuals caught. Five tagged fish were $<80 \mathrm{~cm}$ FL.

Tags were programmed to remain attached to the fish for at least $21 \mathrm{~d}$, after which they would release, float to the surface, and begin broadcasting data to satellites. We selected $21 \mathrm{~d}$ as the time frame that mortality of green sturgeon could be attributed to the effects of trawl capture, on the basis of a literature survey of similar approaches. Because of logistics involved with programming and transport to fishermen and observers, tags were sometimes deployed for more than $21 \mathrm{~d}$.

We used multiple lines of evidence to determine the fate of tagged individuals: location, depth, temperature, and acceleration data. The GPS location at release of the tagged fish, as recorded by the tag, was compared with the time and estimated location of the first PSAT broadcast. Variable depth recordings that were not characterized by regular, repeating tidal signatures indicated swimming. In contrast, depth recordings from PSATs on dead fish had a tidal signature (as in the record from

\footnotetext{
${ }^{5}$ NWFSC (Northwest Fisheries Science Center). 2019. 2019 training manual: West Coast Groundfish Observer Program, 529 p. Northwest Fish. Sci. Cent., Natl. Mar. Fish. Serv., NOAA, Seattle, WA. [Available from website.]
} 
the PSAT deployment on the known dead white sturgeon). Data from temperature sensors often indicate the difference between the cooler ocean waters near the release location and the warmer waters of the San Francisco Bay Delta. Accelerometer data for each individual were classified by our trained algorithm. For each tag deployment, we plotted the classified accelerometer data by time and a smoothing trend line (moving average of 200 readings) to visualize any trends in activity during a deployment.

For each PSAT deployment, we summarized these lines of evidence, wrote a narrative of what likely happened to each fish after release, and ultimately classified each deployment as a survival or a mortality. We then implemented the Kaplan-Meier survival estimator-in the package survival, vers. 2.38 (Therneau and Grambsch, 2000; Therneau, 2015), in statistical software R, vers. 3.3.2 ( $\mathrm{R}$ Core Team, 2016) - to determine the proportion of individuals that had survived $21 \mathrm{~d}(504 \mathrm{~h})$ following capture and release from the fishery (Kaplan and Meier, 1958).

Although not the central goal of our study, we used stepwise logistic regression analysis (RStudio, vers. 1.0.44, RStudio Inc., Boston, MA) to evaluate the association of potential explanatory variables (e.g., tow duration, tow depth, fish length, and processing time; Suppl. Table 2) with postrelease survival. We included continuous variables that were consistently recorded and had a wide range of values. Null values were excluded from the logistic regression model. We assumed that a $P$-value $\leq 0.05$ indicates that a result is statistically significant.

\section{Results}

\section{Characterizing sensor readings for green sturgeon with known fates}

Temperature and depth data and accelerometer readings from PSAT deployments on known dead and living sturgeon were downloaded, plotted, and visually examined. The PSAT deployed on the known dead white sturgeon recorded consistently cool water temperatures (approximately $12^{\circ} \mathrm{C}$ ), and the depth record indicated tidal fluctuations consistent with a stationary carcass on the seafloor. Accelerometer data indicate that the tag was almost entirely upright with minimal lateral sway. The PSATs deployed on 3 green sturgeon known to be alive all recorded shallow depths $(<1 \mathrm{~m})$ and stable water temperatures $\left(18^{\circ} \mathrm{C}\right)$ experienced in the tank. Accelerometer readings were variable, indicating the occurrence of periods of apparent swimming (lateral swaying) and stationary periods during which the tag was upright (see examples in Supplementary Figures 1-3).

\section{Training and testing the algorithm}

The model correctly classified $97.7 \%$ and $96.3 \%$ of the dead individuals in the training and testing data sets, respectively (Table 1). More living than dead individuals were misclassified for both the training $(\sim 7 \%)$ and testing $(6 \%)$ data sets (Table 1). Overall, the model accurately classified $96.9 \%$ of the data points, with better classification accuracy for the fates of tagged fish determined to be dead $(98.7 \%)$ than for those determined to be alive $(88.0 \%)$.

\section{Classifying fates of captured green sturgeon}

Fishermen attached PSATs to 19 green sturgeon, and observers tagged 57 fish. Of these 76 PSAT deployments, 51 yielded sufficient data to contribute to our analysis. Of these 51 data sets, 37 were from recovered tags and 14 were from broadcasted data summaries. Examples of the accelerometer, depth, and temperature data from PSAT deployments can be found in Supplementary Figures 1-3. The length of tagged fish ranged from 69 to $135 \mathrm{~cm} \mathrm{FL}$ (median: $98 \mathrm{~cm} \mathrm{FL)} \mathrm{(Fig.} \mathrm{3).} \mathrm{For} 3$ of the 5 fish $<80 \mathrm{~cm} \mathrm{FL,}$ data from PSAT deployments could not be used for classification (because of insufficient data recovery); the other 2 fish were determined to have survived for $21 \mathrm{~d}$. A median of $7.5 \mathrm{~min}$ was estimated for the time required to process and tag an individual (Suppl. Table 2). This value does not represent total time out of the water, given the additional time necessary to extract a green sturgeon from a haul and ensure safe conditions for processing.

After release, green sturgeon often entered San Francisco Bay or remained in nearshore waters of the Pacific Ocean and close to their release locations. Citizens found and returned tags that had popped off and drifted to shore. These tags were generally recovered from ocean beaches between Drakes Bay and Half Moon Bay (Fig. 1). Within the San Francisco Bay Delta, PSATs were recovered from directly below the Golden Gate Bridge to inland waters at the confluence of the Sacramento and San Joaquin Rivers. Some deployments yielded both broadcast summaries and archival data; in these cases, we used the more complete archival data (see the "Discussion" section). For the 51 deployments with sufficient data, 24 tags were recovered or had first broadcasts within the San Francisco Bay Delta, and 21 tags were recovered or had first broadcasts in the ocean (near their recovery locations). For the other 6 deployments, the recovery or first broadcast location of the tag could not be determined.

The length of time that a tag remained attached to a fish ranged from 3 to $47 \mathrm{~d}(83-1128 \mathrm{~h})$. In most cases, tags were attached to the fish for more than $21 \mathrm{~d}$. Three tags detached prematurely because of poor tag attachment and were omitted from the study at the time of detachment (categorized as censored; Suppl. Table 2). Of the 51 green sturgeon for which data were recovered, we estimated that 11 died, 9 within $4.5 \mathrm{~d}(107 \mathrm{~h})$ of release, and 2 died after the 21-d (504-h) study period at $569 \mathrm{~h}$ and $679 \mathrm{~h}$ after release (Table 2). We, therefore, reject the hypothesis that there is no postrelease mortality of green sturgeon captured as bycatch in this fishery. The estimated survival rate was $82 \%$ (95\% confidence interval: 72-94\%) during the 21-d study period.

The results of analysis with the full regression model indicate that mortality (within $504 \mathrm{~h}$ postrelease) was not significantly related to tow duration $(P=0.6438)$, tow 


\section{Table 1}

Accuracy of the support vector machine (SVM) model in classifying an individual green sturgeon (Acipenser medirostris) as dead or alive. We collected accelerometer data from pop-up satellite archival tags (PSATs) deployed on known living and dead sturgeon. Data were derived from 2 experiments conducted in 2015. In the first, we attached PSATs to 3 living, captive green sturgeon (approximately 90, 100, and $110 \mathrm{~cm} \mathrm{FL}$ ) held for $7.5 \mathrm{~h}$ in a 1.5-m-deep circular tank with a 4-m diameter. In the second, we attached a PSAT to a dead white sturgeon (A. transmontanus) (104 cm FL) in the Pacific Ocean off northern California for $96 \mathrm{~h}$. We obtained 284 accelerometer readings from the live green sturgeon and 1392 accelerometer readings from the dead white sturgeon. The accelerometer readings were randomly divided into training and testing data samples at a ratio of 4:1 (training:testing) and used to develop a SVM model to classify each accelerometer reading as representing a living or dead sturgeon. The data in this table compare the actual and predicted (by using the SVM model) number and percentage of accelerometer readings classified as representing a living or dead sturgeon.

Overall accuracy of classification by SVM

\begin{tabular}{|c|c|c|c|}
\hline & \multirow[b]{2}{*}{ Classification } & \multicolumn{2}{|c|}{$\begin{array}{c}\text { Predicted classification } \\
\text { (no. of accelerometer readings) }\end{array}$} \\
\hline & & Dead & Alive \\
\hline Actual classification (no. of accelerometer readings) & $\begin{array}{l}\text { Dead } \\
\text { Alive }\end{array}$ & $\begin{array}{r}1374 \\
34 \\
\end{array}$ & $\begin{array}{r}18 \\
250 \\
\end{array}$ \\
\hline \multicolumn{4}{|c|}{ Accuracy of classification by SVM: training data } \\
\hline & & \multicolumn{2}{|c|}{$\begin{array}{l}\text { Predicted classification (percentage } \\
\text { of accelerometer readings) }\end{array}$} \\
\hline & Classification & Dead & Alive \\
\hline Actual classification (percentage of accelerometer readings) & $\begin{array}{l}\text { Dead } \\
\text { Alive }\end{array}$ & $\begin{array}{r}97.7 \% \\
2.3 \% \\
\end{array}$ & $\begin{array}{r}7 \% \\
93 \% \\
\end{array}$ \\
\hline \multicolumn{4}{|c|}{ Accuracy of classification by SVM: testing data } \\
\hline & & \multicolumn{2}{|c|}{$\begin{array}{l}\text { Predicted classification (percentage } \\
\text { of accelerometer readings) }\end{array}$} \\
\hline & Classification & Dead & Alive \\
\hline Actual classification (percentage of accelerometer readings) & $\begin{array}{l}\text { Dead } \\
\text { Alive }\end{array}$ & $\begin{array}{r}96.3 \% \\
3.7 \%\end{array}$ & $\begin{array}{r}6 \% \\
94 \%\end{array}$ \\
\hline
\end{tabular}

depth $(P=0.5623)$, fish length $(P=0.5424)$, processing time $(P=0.7214)$, air temperature $(P=0.8808)$, or water temperature $(P=0.9266)$. These variables were dropped by the model in further analysis with the stepwise regression model. Catch weight was not included in this analysis because of the frequency of associated null values. The time that elapsed between the end of the tow (i.e., the start of the haul back of the trawl net) and the release of the tagged green sturgeon (Suppl. Table 2) remained in the final model and significantly affected postrelease survival $(P=0.0315)$. It should be noted that the same relationship was found when the model considered mortality occurring more than $504 \mathrm{~h}$ after release.

\section{Discussion}

We successfully developed a method for interpreting archival tagging data to classify the fate of tagged green sturgeon. Our approach is unique in that it relies primarily on an algorithm trained by data from deployments of PSATs on individuals with known fates rather than on assessments of mortality based on continuous or threshold depth or on descent of depth readings (Poisson et al., 2014; Hutchinson et al., 2015). Given that sturgeon are mostly bottom dwelling and can sometimes occupy a range of depths that could be perceived as constant (i.e., within the range of error of the depth sensor), we developed the approach detailed herein. Our approach is similar to that developed by Whitney et al. (2016) in its use of accelerometer data in combination with depth and temperature data.

Our success in arriving at a survival estimate can be attributed to a few factors. Foremost was the cooperation with fishermen and observers, which provided a low-cost mechanism for tagging green sturgeon without additional research or vessel effort and a study design that tested our hypothesis in regular fishing conditions. The high rate of tag retrieval was also important. Data obtained from recovered tags were sufficient for determining mortality or survival $90 \%$ of the time; broadcast data were 


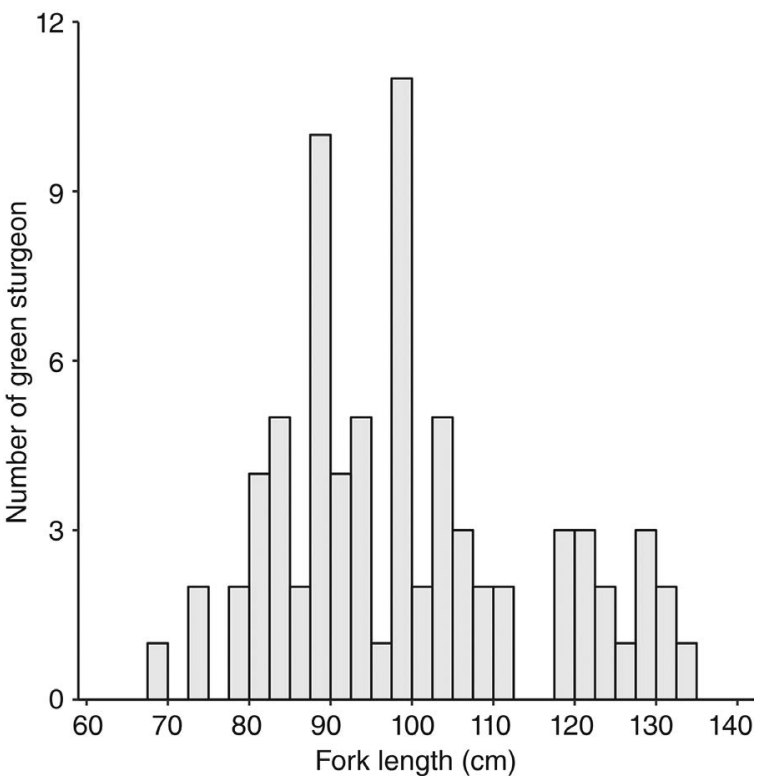

Figure 3

Length-frequency histogram for green sturgeon (Acipenser medirostris) tagged after capture as bycatch between May 2015 and September 2016 on 6 bottom-trawl vessels that targeted California halibut (Paralichthys californicus) off San Francisco and Half Moon Bay.

sufficient for determining mortality or survival $70 \%$ of the time. The location of our study was such that many of our tags were found on beaches near recreational and urban areas. Broadcast data were inferior to archived data from the returned tags because weather often hindered satellite transmissions, leading to gaps in the broadcast data summaries. In future studies, the use of broadcast data in other areas or from different tags may result in more complete broadcast data. We also benefitted from baseline information from a previous study of green sturgeon that used pop-up satellite tagging (Erickson and Hightower, 2007). Hence, signatures within our data, including tidal patterns and evidence of animals moving into warmer or cooler waters, helped determine the fates of sturgeon.

The temperature and depth data as well as the location of first broadcast or recovery of tags indicate that some green sturgeon entered the environment of the San Francisco Bay Delta after being tagged and released in the Pacific Ocean. Given previous research (Anderson et al., 2017), the majority of these fish were likely Southern DPS individuals that had reared in the delta environment. The results of earlier work indicate that Southern DPS green sturgeon rear in freshwater and estuarine environments for up to 4 years before transitioning to saltwater environments and migrating up the coast, returning to freshwater only to spawn (Beamesderfer et al., 2007). Our research adds evidence to published studies (e.g., Lindley et al., 2011; Miller, 2017) that Southern DPS green sturgeon

\section{Table 2}

Kaplan-Meier estimates of survival of green sturgeon (Acipenser medirostris) as each dead individual exits the study. Between May 2015 and September 2016, individuals were captured as bycatch and tagged on 6 bottom-trawl vessels that targeted California halibut (Paralichthys californicus) in nearshore waters of the Pacific Ocean just west of the San Francisco Bay Delta. The number at risk is the number of green sturgeon with tags still attached for at least the corresponding hours after release. For example, 16 individuals had tags that remained attached for more than $678 \mathrm{~h}$ after release. We attributed any mortality occurring before $504 \mathrm{~h}$ to the effects of trawl capture. $\mathrm{SE}=$ standard error of the mean; $\mathrm{CI}=$ confidence interval.

\begin{tabular}{ccccc}
\hline $\begin{array}{c}\text { Hours after } \\
\text { release }\end{array}$ & $\begin{array}{c}\text { Number at } \\
\text { risk }\end{array}$ & $\begin{array}{c}\text { Survival } \\
\text { rate }\end{array}$ & SE & $95 \%$ CI \\
\hline 0.53 & 51 & 0.98 & 0.02 & $0.94-1.00$ \\
4.33 & 50 & 0.96 & 0.03 & $0.91-1.00$ \\
4.80 & 49 & 0.94 & 0.03 & $0.88-1.00$ \\
6.58 & 48 & 0.92 & 0.04 & $0.85-1.00$ \\
8.62 & 47 & 0.90 & 0.04 & $0.82-0.99$ \\
14.63 & 46 & 0.88 & 0.05 & $0.80-0.98$ \\
17.85 & 45 & 0.86 & 0.05 & $0.77-0.96$ \\
104.09 & 43 & 0.84 & 0.05 & $0.75-0.95$ \\
107.34 & 42 & 0.82 & 0.05 & $0.72-0.94$ \\
569.05 & 27 & 0.79 & 0.06 & $0.68-0.92$ \\
678.67 & 16 & 0.74 & 0.07 & $0.61-0.90$
\end{tabular}

move in and out of San Francisco Bay before maturing and migrating to northern estuaries.

Finding an appropriate method to acquire accelerometer data for sturgeon was a challenge. Although we tagged captive green sturgeon, other options could provide data to refine our results. Captive white sturgeon in commercial aquariums with tanks of much greater volume could be used, but fish in such tanks are often not in the size range of fish tagged in our field study. Moser et al. (2018) provided accelerometer data from live, free-swimming green sturgeon shortly after capture and release from gill nets in Willapa Bay, Washington. These green sturgeon ranged from 45 to $167 \mathrm{~cm} \mathrm{FL,} \mathrm{with} \mathrm{the} \mathrm{majority} \mathrm{of} \mathrm{those} \mathrm{fish} \mathrm{larger}$ than the green sturgeon in our study. The data of Moser et al. (2018) were also collected by tags that were not freely moving but held in place along the body axis. Despite these differences, it might be possible to incorporate elements of their accelerometer data to inform our classification model in the future. Using PSATs on green sturgeon from gill-net bycatch could provide an interesting comparison and insights into the relative threats of these 2 fisheries to green sturgeon.

Additional studies and modeling are needed to understand the effects of the estimated level of postrelease mortality on the threatened Southern DPS. Population estimates based on adult abundance have recently been developed for the Southern DPS (Mora et al., 2018), allowing evaluation of population-level impacts of bycatch mortality on status and recovery. The California 
halibut bottom-trawl fishery primarily interacts with immature individuals of the Southern DPS (Anderson et al., 2017; Richerson et al. ${ }^{3}$ ). With some additional efforts, data from this fishery could be used to refine the overall estimate of abundance for the Southern DPS and allow for a more robust analysis of effects from postrelease mortality. It should be noted that fishery bycatch mortality is only one factor that affects the Southern DPS; recovery will require improved access to spawning and rearing areas $\left(\mathrm{NMFS}^{2}\right)$.

Our study was not designed to examine specific factors contributing to postrelease mortality and involved green sturgeon caught during normal fishing operations. Although we collected ancillary data on each haul for which green sturgeon were tagged, hauls and fishing effort were not sufficiently dispersed across the different variables, sample sizes were small, and data were recorded inconsistently for some variables. Therefore, our inability to identify certain factors as significant contributors to postrelease mortality should not be taken as conclusive evidence that these factors have no effect. In our study, the total time that a tagged sturgeon spent in the net during haul back and on deck for processing and tagging was the only variable that may have significantly affected mortality. Given this result and literature evidence (e.g., Parker et al., 2003; Davis and Parker, 2004; Beardsall et al., 2013; Cook et al., 2019), WCGOP protocols have been changed to minimize time out of water for green sturgeon encountered in the fishery. Creating onboard environments conducive to improved survival (e.g., shade, use of a hose or other water source to keep individuals continuously wet and cool, and possible construction of live wells) will also be explored.

A rational next step is to design a properly stratified study to evaluate the contribution of different factors to the capture and survival of green sturgeon in the bottomtrawl fishery that targets California halibut. A future study could also incorporate an examination of stress responses (Lankford et al., 2005; Webb and Doroshov, 2011; Beardsall et al., 2013; McLean et al., 2019). Reports by fishermen and observers further indicate that California sea lions (Zalophus californianus) and Steller sea lions (Eumetopias jubatus) are sometimes present in the area where green sturgeon are released. Postrelease predation could be a factor (Cook et al., 2019). Ingestion of sturgeon fitted with pop-up satellite tags could be inferred from tag data that indicates movement patterns (e.g., Kerstetter et al., 2004) or stomach temperature (e.g., Béguer-Pon et al., 2012) of a predator.

Trawl-net modifications that reduce encounters or lethal interactions with green sturgeon should also be explored, given that bycatch avoidance is the best mechanism to reduce postrelease mortality. Research should be undertaken in collaboration with fishermen and with the objective of maintaining a viable fishery while reducing interactions with green sturgeon. Although examples of trawl-net modifications meant to exclude sturgeon are lacking, visual studies (e.g., Piasente et al., 2004; Jones et al., 2008) could inform designs that minimize interactions and maintain viability of the target fishery.

\section{Acknowledgments}

This project was supported by the NMFS Southwest Fisheries Science Center and National Cooperative Fisheries Fund and by the NMFS West Coast Region and Office of Protected Resources. Fishermen targeting California halibut and WCGOP observers were essential to the success of this work. We are grateful to R. Morse (West Coast Region affiliate) for his assistance with geographical information system analyses and map generation. We dedicate this work to our colleague E. Mora, who passed away on 22 May 2019. He was the powerhouse behind the study, a giant in the world of green sturgeon research, and a one-of-a-kind colleague.

\section{Literature cited}

Anderson, E. C., T. C. Ng, E. D. Crandall, and J. C. Garza.

2017. Genetic and individual assignment of tetraploid green sturgeon with SNP assay data. Conserv. Genet. 18: 1119-1130. Crossref

ASSRT (Atlantic Sturgeon Status Review Team).

2007. Status review of Atlantic sturgeon (Acipenser oxyrinchus oxyrinchus), 174 p. Report to Northeast Reg. Off., Natl. Mar. Fish. Serv., NOAA, Gloucester, MA. [Available from website.]

Beamesderfer, R. C. P., M. L. Simpson, and G. J. Kopp.

2007. Use of life history information in a population model for Sacramento green sturgeon. Environ. Biol. Fish. 79: 315-337. Crossref

Beardsall, J. W., M. F. McLean, S. J. Cooke, B. C. Wilson, M. J. Dadswell, A. M. Redden, and M. J. W. Stokesbury.

2013. Consequences of incidental otter trawl capture on survival and physiological condition of threatened Atlantic sturgeon. Trans. Am. Fish. Soc. 142:1202-1214. Crossref

Béguer-Pon, M., J. Benchetrit, M. Castonguay, K. Aarestrup, S. E. Campana, M. J. W. Stokesbury, and J. J. Dodson.

2012. Shark predation on migrating adult American eels (Anguilla rostrata) in the Gulf of St. Lawrence. PLoS ONE 7(10):e46830. Crossref

Bishop, C. M.

2006. Pattern recognition and machine learning, 738 p. Springer-Verlag, New York.

Breece, M. W., D. A. Fox, K. J. Dunton, M. G. Frisk, A. Jordaan, and M. J. Oliver.

2016. Dynamic seascapes predict the marine occurrence of an endangered species: Atlantic sturgeon Acipenser oxyrinchus oxyrinchus. Methods Ecol. Evol. 7:725-733. Crossref

Brooke, S. G., L. L. Desfosse, and W. A. Karp.

2012. Estimating overall fish bycatch in U.S. commercial fisheries. Mar. Fish. Rev. 74(3):1-5.

Burges, C. J. C.

1998. A tutorial on support vector machines for pattern recognition. Data Min. Knowl. Disc. 2:121-167. Crossref

Campana, S. E., W. Joyce, M. Fowler, and M. Showell.

2016. Discards, hooking, and post-release mortality of porbeagle (Lamna nasus), shortfin mako (Isurus oxyrinchus), and blue shark (Prionace glauca) in the Canadian pelagic longline fishery. ICES J. Mar. Sci. 73:520-528. Crossref

Collins, M. R., S. G. Rogers, T. I. J. Smith, and M. L. Moser.

2000. Primary factors affecting sturgeon populations in the southeastern United States: fishing mortality and degradation of essential habitats. Bull. Mar. Sci. 66:917-928. 
Cook, K. V., A. J. Reid, D. A. Patterson, K. A. Robinson, J. M. Chapman, S. G. Hinch, and S. J. Cooke.

2019. A synthesis to understand responses to capture stressors among fish discarded from commercial fisheries and options for mitigating their severity. Fish Fish. 20:25-43. Crossref

Davies, R. W. D., S. J. Cripps, A. Nickson, and G. Porter.

2009. Defining and estimating global marine fisheries bycatch. Mar. Policy 33:661-672. Crossref

Davis, M. W.

2002. Key principles for understanding fish bycatch discard mortality. Can. J. Fish. Aquat. Sci. 59:1834-1843. Crossref

Davis, M. W., and S. J. Parker.

2004. Fish size and exposure to air: potential effects on behavioral impairment and mortality rates in discarded sablefish. North Am. J. Fish. Manage. 24:518-524. Crossref

Davis, M. W., B. L. Olla, and C. B. Schreck.

2001. Stress induced by hooking, net towing, elevated sea water temperature and air in sablefish: lack of concordance between mortality and physiological measures of stress. J. Fish Biol. 58:1-15. Crossref

Dunton, K. J., A. Jordaan, D. O. Conover, K. A. McKown,

L. A. Bonacci, and M. G. Frisk.

2015. Marine distribution and habitat use of Atlantic sturgeon in New York lead to fisheries interactions and bycatch. Mar. Coast. Fish. 7:18-32. Crossref

Erickson, D. L., and J. E. Hightower.

2007. Oceanic distribution and behavior of green sturgeon. Am. Fish. Soc. Symp. 56:197-211.

Federal Register.

2006. Endangered and threatened wildlife and plants: threatened status for southern distinct population segment of North American green sturgeon. Fed. Reg. 71:17757-17766. [Available from website.]

Gale, M. K., S. G. Hinch, and M. R. Donaldson.

2013. The role of temperature in the capture and release of fish. Fish Fish. 14:1-33. Crossref

Hoolihan, J. P., J. Luo, F. J. Abascal, S. E. Campana, G. De Metrio,

H. Dewar, M. L. Domeier, L. A. Howey, M. E. Lutcavage,

M. K. Musyl, et al.

2011. Evaluating post-release behaviour modification in large pelagic fish deployed with pop-up satellite archival tags. ICES J. Mar. Sci. 68:880-889. Crossref

Hutchinson, M. R., D. G. Itano, J. A. Muir, and K. N. Holland.

2015. Post-release survival of juvenile silky sharks captured in a tropical tuna purse seine fishery. Mar. Ecol. Prog. Ser. 521:143-154. Crossref

IUCN (International Union for Conservation of Nature).

2018. The IUCN Red List of Threatened Species. Vers. 2018-1. [Available from website, accessed July 2018.]

Johnson, T. R., and W. L. T. van Densen.

2007. Benefits and organization of cooperative research for fisheries management. ICES J. Mar. Sci. 64:834-840. Crossref

Jones, E. G., K. Summerbell, and F. O’Neill.

2008. The influence of towing speed and fish density on the behavior of haddock in a trawl cod-end. Fish. Res. 94:166174. Crossref

Kaplan, E. L., and P. Meier.

1958. Nonparametric estimation from incomplete observations. J. Am. Stat. Assoc. 53:457-481. Crossref

Kerstetter, D. W., J. J. Polovina, and J. E. Graves.

2004. Evidence of shark predation and scavenging on fishes equipped with pop-up satellite archival tags. Fish. Bull. 102:750-756.

Lankford, S. E., T. E. Adams, R. A. Miller, and J. J. Cech Jr. 2005. The cost of chronic stress: impacts of a nonhabituating stress response on metabolic variables and swimming performance in sturgeon. Physiol. Biochem. Zool. 78: 599-609. Crossref

Lindley, S. T., D. L. Erickson, M. L. Moser, G. Williams, O. P. Langness, B. W. McCovey Jr., M. Belchik, D. Vogel, W. Pinnix, J. T. Kelly, et al.

2011. Electronic tagging of green sturgeon reveals population structure and movement among estuaries. Trans. Am. Fish. Soc. 140:108-122.

Mandelman, J. W., A. M. Cicia, G. W. Ingram Jr., W. B. Driggers III, K. M. Coutre, and J. A. Sulikowski.

2013. Short-term post-release mortality of skates (family Rajidae) discarded in a western North Atlantic commercial otter trawl fishery. Fish. Res. 139:76-84. Crossref

McLean, M. F., M. K. Litvak, S. J. Cooke, K. C. Hanson,

D. A. Patterson, S. G. Hinch, and G. T. Crossin.

2019. Immediate physiological and behavioural response from catch-and-release of wild white sturgeon (Acipenser transmontanus Richardson, 1836). Fish. Res. 214:65-75. Crossref

Miller, E. A.

2017. Niche partitioning by green sturgeon (Acipenser medirostris) and white sturgeon (A. transmontanus) in the San Francisco Estuary and Sacramento River. Ph.D. diss., 174 p. Univ. Calif. Davis, Davis, CA.

Mora, E. A., R. D. Battleson, S. T. Lindley, M. J. Thomas, R. Bellmer, L. J. Zarri, and A. P. Klimley.

2018. Estimating the annual spawning run size and population size of the Southern Distinct Population Segment of green sturgeon. Trans. Am. Fish. Soc. 147:195-203. Crossref

Moser, M. L., S. C. Corbett, B. J. Burke, and O. P. Langness.

2018. Potential for use of accelerometers to monitor green sturgeon Acipenser medirostris (Ayres, 1854) behavior after handling. J. Appl. Ichthyol. 34:405-411. website

Murphy, K. P.

2012. Machine learning: a probabilistic perspective, $1104 \mathrm{p}$. MIT Press, Cambridge, MA.

NMFS (National Marine Fisheries Service).

2015. Southern distinct population segment of the North American green sturgeon. 5-year review: summary and evaluation, 38 p. West Coast Reg., Natl. Mar. Fish. Serv., NOAA, Long Beach, CA. [Available from website.]

Olla, B. L., M. W. Davis, and C. B. Schreck.

1997. Effects of simulated trawling on sablefish and walleye pollock: the role of light intensity, net velocity and towing duration. J. Fish Biol. 50:1181-1194. Crossref

Parker, S. J., P. S. Rankin, R. W. Hannah, and S. B. Schreck.

2003. Discard mortality of trawl-caught lingcod in relation to tow duration and time on deck. North Am. J. Fish. Manage. 23:530-542. Crossref

Pedregosa, F., G. Varoquaux, A. Gramfort, V. Michel, B. Thirion, O. Grisel, M. Blondel, P. Prettenhofer, R. Weiss, V. Dubourg, et al. 2011. Scikit-learn: machine learning in Python. J. Mach. Learn. Res. 12:2825-2830.

Piasente, M., I. A. Knuckey, S. Eayrs, and P. E. McShane.

2004. In situ examination of the behaviour of fish in response to demersal trawl nets in an Australian trawl fishery. Mar. Freshw. Res. 55:825-835. Crossref

Pikitch, E. K., P. Doukakis, L. Lauck, P. Chakrabarty, and D. L. Erickson.

2005. Status, trends and management of sturgeon and paddlefish fisheries. Fish Fish. 6:233-265. Crossref

Poisson, F., J. D. Filmalter, A.-L. Vernet, and L. Dagorn.

2014. Mortality rate of silky sharks (Carcharhinus falciformis) caught in the tropical tuna purse seine fishery in the Indian Ocean. Can. J. Fish. Aquat. Sci. 71:795-798. Crossref 
Raby, G. D., J. R. Packer, A. J. Danylchuk, and S. J. Cooke.

2014. The understudied and underappreciated role of predation in the mortality of fish released from fishing gears. Fish Fish. 15:489-505. Crossref

\section{Raschka, S.}

2015. Python machine learning, 454 p. Packt Publishing, Birmingham, UK

$\mathrm{R}$ Core Team.

2016. R: a language and environment for statistical computing. R Foundation for Statistical Computing, Vienna, Austria. [Available from website, accessed November 2016]

Stein, A. B., K. D. Friedland, and M. Sutherland.

2004. Atlantic sturgeon marine distribution and habitat use along the Northeastern coast of the United States. Trans. Am. Fish. Soc. 133:527-537. Crossref

Sugiyama, M.

2016. Introduction to statistical machine learning, $534 \mathrm{p}$. Morgan Kaufman, Waltham, MA.

Suuronen, $\mathrm{P}$.

2005. Mortality of fish escaping trawl gears. FAO Fish. Tech. Pap. 478, 72 p. FAO, Rome.

Suuronen, P., and D. L. Erickson.

2010. Mortality of animals that escape fishing gears or are discarded after capture: approaches to reduce mortality. In Behavior of marine fishes: capture process and conservation challenges (P. He, ed.), p. 265-294. Blackwell Publishing Ltd., Ames, IA.

Therneau, T. M.

2015. A package for survival analysis in S. Vers. 2.38. [Available from website, accessed May 2017.]
Therneau, T. M., and P. M. Grambsch. 2000. Modeling survival data: extending the Cox model, $350 \mathrm{p}$. Springer, New York.

Watt, J., R. Borhani, and A. K. Katsaggelos. 2016. Machine learning refined: foundations, algorithms, and applications, 298 p. Cambridge Univ. Press, Cambridge, UK.

Webb, M. A. H., and S. I. Doroshov.

2011. Importance of environmental endocrinology in fisheries management and aquaculture of sturgeons. Gen. Comp. Endocrinol. 170:313-321. Crossref

Weltersbach, M. S., and H. V. Strehlow.

2013. Dead or alive-estimating post-release mortality of Atlantic cod in the recreational fishery. ICES J. Mar. Sci. 70:864-872. Crossref

Whitney, N. M., C. F. White, A. C. Gleiss, G. D. Schwieterman, P. Anderson, R. E. Hueter, and G. B. Skomal.

2016. A novel method for determining post-release mortality, behavior, and recovery period using acceleration data loggers. Fish. Res. 183:210-221. Crossref

Wilson, S. M., G. D. Raby, N. J. Burnett, S. G. Hinch, and S. J. Cooke. 2014. Looking beyond the mortality of bycatch: sublethal effects of incidental capture on marine animals. Biol. Conserv. 171:61-72. Crossref

Yochum, N., R. M. Starr, and D. E. Wendt.

2011. Utilizing fishermen knowledge and expertise: keys to success for collaborative fisheries research. Fisheries 36:593-605. Crossref 